\title{
A ELEIÇÃO DE ISRAEL NA TORÁ
}

\author{
Suzana Chwarts*
}

\section{Resumo}

O presente artigo consiste em uma explanação dos diferentes sentidos e da complexidade do conceito de eleição na Torá, por meio dos quais podemos apreender um pouco das distintas visões de mundo expressas nesses livros, levando-se em conta que todas elas são representações da auto percepção e consciência do Israel antigo, cujo núcleo reside no princípio de que Deus se relaciona com seu povo não por meio de relações naturais, mas de relações contratuais.

Palavras-chave: Torá, eleição, santidade, Israel bíblico

\section{Abstract}

This article is an explanation of the different senses and the complexity of the concept of Election in the Torah, through which we can learn of different worldviews expressed in these books, taking into account that they are all representations of the self-perception and awareness of ancient Israel, whose core is the principle that God relates to his people not through a natural relationship but a contractual one.

Keywords: Torá, election, holiness, biblical Israel

* Arqueóloga bíblica e professora doutora de Bíblia Hebraica na Faculdade de Filosofia, Letras e Ciências Humanas da Universidade de São Paulo. <schwarts@usp.br> 
$\mathbf{A}^{\mathrm{i}}$ ideia da eleição de Israel encontra-se principalmente nos livros da Torá. Para apreciar os diferentes sentidos e a complexidade desta ideia é necessário apreender as diferentes visões de mundo expressas nos livros, levando-se em conta que todas elas são representações da auto percepção e consciência do Israel antigo, cujo núcleo reside no princípio de que Deus se relaciona com seu povo não por meio de relações naturais, mas de relações contratuais.

Embora Deus tenha firmado uma aliança eterna com os patriarcas, o conceito de eleição se aplica a Israel quando este é definido como povo, uma unidade corporativa designada pelos nomes: bnei-israel, 'am israel, qahal israel, ou ainda 'adat bnei-israel.

É sabido hoje que as relações contratuais firmadas entre o povo de Israel e seu Deus seguem o modelo dos contratos de suserania e vassalagem neoassírios e hititas, com estipulações, penalidades e benefícios específicos.

$\mathrm{Na}$ base de todos os contratos, a ideia primordial: a eleição não é incondicional.

Nesta aparente fragilidade concentra-se, no entanto, a força interna de Israel, o seu ímpeto em direção a um aprimoramento perene do indivíduo e do cosmos, que constitui a marca registrada do judaísmo até os dias atuais.

A eleição condicional descarta as noções de superioridade ou santidade inerentes ao povo de Israel.

É um conceito que pertence a um Israel idealizado, definido pela total submissão a Deus e pelo cumprimento perfeito de seus mandamentos. Esta visão encontra em Maimônides seu maior defensor. Nas tradições do Êxodo, a eleição é expressa por meio de ideias que se complementam entre si. Um dos princípios que regem a eleição teológica é o da família patriarcal, ancorada nos conceitos de primogenitura e propriedade; ou seja, o significado teológico está calcado na estrutura social de Israel, com seu elenco peculiar de direitos e deveres. 
Assim, lemos em Êxodo (Ex) 4:22-23:1

Então dirás a Faraó: Assim diz h':

Israel é meu filho, meu primogênito. (bə·n̂̂ $\underline{b} \partial \cdot \underline{k} \bar{o} \cdot r \hat{\imath}$

yiśr $r \bar{a} \cdot \hat{e}$ ê)

E eu te tenho dito:

Deixa ir o meu filho, para que me sirva (šal $\cdot l a h$ 'et- bo·nî $w \partial \cdot y a \cdot a \underline{b} \cdot \underline{d} \hat{e} \cdot n \hat{\imath})$

mas tu recusaste deixá-lo ir;

eis que eu matarei a teu filho, o teu primogênito.

A razão de ser de Israel é servir a Deus como um primogênito serve a casa de seu pai, constituindo o elo de continuidade da linhagem patriarcal, ao contrário dos outros filhos consanguíneos que fundam sub-linhagens aparentadas.

A ideia bíblica é que o primogênito é fruto de uma escolha deliberada que desafia a hierarquia etária dos filhos. Da mesma forma que Israel não é o mais antigo dos povos, Isaac, e não Ismael, é o primogênito, Jacó e não Esaú.

Uma outra elaboração do conceito de eleição terá por base o princípio de valor implícito, mérito e lealdade, além do sentido explícito de propriedade, como se vê na passagem a seguir.

Agora, pois, se diligentemente ouvirdes a minha voz e guardardes a minha aliança, então sereis a minha propriedade peculiar dentre todos os povos (wih.ŷt.tem

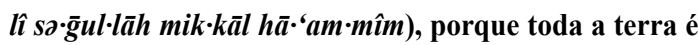
minha. (Ex 19:5-6)

O termo sa ğulllāh, que corresponde ao acádico sikiltum, pode ser traduzido como propriedade peculiar, valiosa, denotando o direito exclusivo à posse. Um selo de Alalakh designa seu dono como sikiltum do rei.

1 No presente artigo foi empregada a Versão Revista e Atualizada de João Ferreira de Almeida (Antigo Testamento Poliglota; Edições Vida Nova e Sociedade Bíblica do Brasil, 2003); o tetragramaton foi substituído pela autora pelo signo h' ou pelo termo hebraico adonai, de acordo com as notações massoréticas. 
O versículo seguinte explicita a acepção bíblica de $s \partial \cdot \bar{g} u l \cdot l a ̄ h$.

E vós me sereis um reino sacerdotal e o povo santo

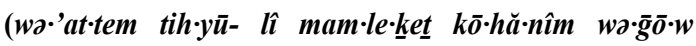
$q \bar{a} \cdot \underline{d} \bar{o} \cdot w \bar{o} s ;) . ~(E x ~ 19: 6)$

Com o termo $q \bar{a} \cdot \underline{d} \bar{o} \cdot w \bar{s} s$ é introduzida a ideia de santidade/separação que marca a singularidade de Israel como nação e reverbera as palavras do vidente Balaão:

Eis um povo que habita à parte e não é classificado entre as nações. ( $\mathrm{Nm} \mathrm{23:7-9)}$

O paralelo entre os termos $k \bar{o} \cdot h \breve{a} \cdot n \hat{\imath} m$ e $q \bar{a} \cdot \underline{d} \bar{o} \cdot w \bar{o} s ̌$ deixa implícito que o povo é santificado à medida que serve seu Deus, como um sacerdote o faz, obedecendo a preceitos e observando regras, alinhando-se ritualisticamente à divindade. O caráter pragmático dessa ideia é evidente.

A santidade de Israel justifica um amplo elenco de admoestações que visam a separar Israel das nações que a precederam na terra de Canaã.

Quando o senhor teu Deus te introduzir na terra a qual passas a possuir, e tiver lançado muitas nações de diante de ti... não farás com elas aliança... nem contrairás matrimônio com os filhos dessas nações; não darás tuas filhas a seus filhos, nem tomarás suas filhas para teus filhos, pois (elas) ${ }^{2}$ fariam desviar teus filhos de mim, para que servissem a outros deuses; a ira do senhor se acenderia contra vós e depressa vos destruiria. Porém assim lhes fareis: derribarei os seus altares, quebrareis suas colunas, cortareis seus postes-ídolos ${ }^{3}$ e queimareis as suas imagens de escultura. Porque tu és um povo

2 Em hebraico: ki yasir 'et binekha me'acharay - o verbo está no masculino singular.

3 Em hebraico: 'ashereihem, ou seja, suas asheras. 
santo a $h$ ', teu Deus; $h$ ', teu Deus te escolheu, para que fosses o seu povo próprio, de todos os povos que há sobre a terra. (Dt 7:1-6)

Israel, um grupo cercado de povos mais numerosos, mais antigos e infinitamente mais poderosos, busca preservar sua identidade, alimentando a ideia de que é um povo separado das nações por seu Deus, e santificado por meio de sua eleição e da outorga dos ensinamentos divinos, os quais devem cumprir e aos quais devem submissão incondicional.

Mas da mesma forma que um sacerdote se desvia do caminho retilíneo traçado por Deus, o povo de Israel é caracterizado como 'am qshe 'oref (Ex 33:5), um povo vaidoso, obtuso, que não se curva ao peso de Deus, a ponto deste se enfurecer e ameaçar feri-los com pestilências e... deserdá-lo.

\section{E disse $h$ ' a Moisés:}

Até quando me provocará este povo?

e até quando não crerá em mim, apesar de todos os sinais que fiz no meio dele?

Com pestilência o ferirei, e o rejeitarei;

e te farei a ti povo maior e mais forte do que este. (Nm 14:11-12)

As regras da eleição ficam claras: se o povo não se curvar e submeter-se à divindade, não ouvir sua voz (que significa obedecê-lo) e cumprir sua aliança, não será um povo de sacerdotes, nem uma propriedade particular, nem o seu primogênito; será um povo deserdado e rejeitado, alvo da ira divina, o mais miserável dos povos.

A condição de Israel como escolhida para pertencer a Deus, ou seja, para servir a Deus, como uma nação de sacerdotes, impõe a esta que seja una e sem mácula: hit'alekh lefanai weheyeh tamim (caminhe à minha frente e seja íntegro, perfeito) é a exigência que Deus faz a Abraão e é também o atributo que diferencia Noé do resto da humanidade pré-diluviana.

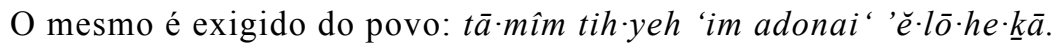


(Dt 18:13). tā'mîm é empregado nos livros da Torá com o sentido de imaculado, para designar um animal apto para o sacrifício.

Se a sua oferta for de gado, trará macho sem defeito (zakhar tā'mîm); à porta da tenda da congregação o trará, para que o homem seja aceito perante o Senhor. (Lv 1:3)

[...] 0 animal deve ser sem defeito para que seja aceitável; nele, não haverá defeito algum. (Lv 22:21)

Também os sacerdotes que oficializam os sacrifícios e as oferendas devem estar isentos de qualquer mum (defeito ou mácula), uma vez que tudo o que está em contato com o mais alto nível de sagrado santifica-se.

[...] o altar será santíssimo; tudo o que o tocar será santo. (Ex 29:37)

Nenhum homem da descendência de Arão, o sacerdote, em quem houver algum defeito se chegará para oferecer ofertas queimadas ao Senhor; ele tem defeito; não se chegará para oferecer o pão de seu Deus... porque tem defeito, para que não profane os meus santuários, porque eu sou o Senhor, que os santifico. (Lv 21:21; 23)

Ser imaculado e caminhar na presença de Deus, a exigência que norteia a consciência religiosa de Israel, implica refletir em todas as atitudes e pensamentos do coração a santidade divina.

Para tal é prescrito um amplo conjunto de preceitos morais em Levíticos (Lv) 19, como honrar pai e mãe, erguer-se perante um ancião, respeitar os cegos e surdos, não guardar vingança no coração, amar o próximo, amar o 
estrangeiro, não fazer mexericos, bem como preceitos dietéticos, sexuais e cultuais destinados a reger todos os aspectos da vida cotidiana da comunidade santificada.

O cumprimento dos preceitos divinos, que condicionam todo o escopo da existência mundana à obediência e à vontade divina, santifica o povo.

Guardai os meus estatutos e cumpri-os. Eu sou o Senhor, que vos santifica. (Lv 20:8)

Com isso, anula-se a esfera do profano - convencional oposto dicotômico de sagrado - na Bíblia hebraica. A Israel só é permitida uma vida santificada; ou nada.

No livro do Deuteronômio, acoplado à reforma religiosa centrada em Jerusalém e à propaganda sociopolítica de Judá, a doutrina da eleição de Israel aparece recoberta por uma pátina de interpretação que busca atenuar a tensão que permeia essa ideia, atribuindo a Deus uma ação explícita de escolha por intermédio do verbo livchor, que figura aqui pela primeira vez associada à ideia de amor, um sentimento sem restrições na Bíblia hebraica, regido por sua própria natureza e não por padrões "politicamente corretos", como o amor de Rebeca por Jacó e de Isaac por Esaú.

Assim, lemos em Deuteronômio (Dt) 10:15:

Tão-somente $h$ ' se agradou de teus pais para os amar

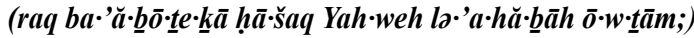
e a vós, descendência deles, escolheu, depois deles

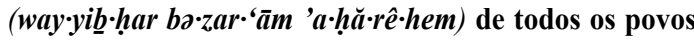

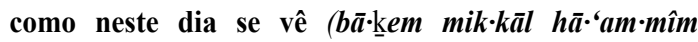

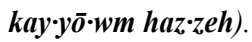

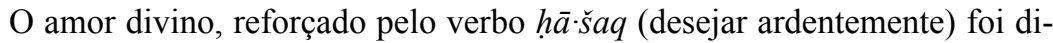
rigido aos patriarcas, mas a eleição, expressa pelo verbo $y i \underline{b} \cdot h a r$, é dirigida à sua descendência.

Esses elementos evidenciam o fato de a divindade ter exercitado sua vonta- 
de livremente, dissociando a eleição dos méritos e das obrigações de Israel.

$\mathrm{Na}$ tradição deuteronômica, ao dispersar os filhos do homem, Deus teria dado a cada nação sua herança e fixado suas fronteiras de acordo com o número dos filhos de Israel ${ }^{4}$, sendo seu povo sua porção, Jacó, a medida de sua herança.

Quando o Altíssimo distribuía as heranças às nações, quando dividia os filhos de Adão uns dos outros, estabeleceu os termos dos povos, conforme o número dos filhos de Israel 5 .

Porque a porção de $h$ 'é o seu povo; Jacó é a parte da sua herança.

Achou-o numa terra deserta, e num ermo solitário cheio de uivos; cercou-o, instruiu-o, e guardou-o como a menina do seu olho.

Como a águia desperta a sua ninhada, move-se sobre os seus filhos, estende as suas asas, toma-os, e os leva sobre as suas asas. (Dt 32:8-11)

As tradições da Torá que versam sobre eleição fazem referência à relação estabelecida entre o povo de Israel e o Deus de Israel; não se identifica nessas tradições a ideia de um Deus universal.

Como se observa nessas passagens, a ideia da santidade/separação do povo não é a tônica da visão deuteronômica de eleição.

Já na visão sacerdotal, ela figura de forma hiperbólica, totalizante, em uma máxima teológica tão desconcertante que gera exegeses dissonantes até os dias de hoje.

Em Levíticos 19:2 lemos:

4 Assim versa o texto massorético; na LXX e nos manuscritos do Mar Morto em vez de bnei israel figura bnei ha'elohim...

5 Versão massorética. 
Fala a toda a congregação dos filhos de Israel, e dize-

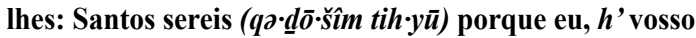

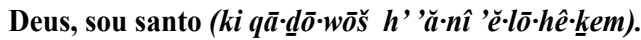

Ou seja, Israel deve refletir em suas atitudes as atribuições de santidade divina - uma ideia essencialmente abstrata - que implica separação, perfeição, integridade, totalidade, algo impossível de cumprir, posto que a natureza humana é imperfeita, algo tantas vezes atestado no próprio relato bíblico.

Essa ideia evidencia sobretudo a distância que separa o homem de Deus!

Essa questão teológica será amplamente discutida pelos profetas clássicos: o que Deus deseja de Israel como seu eleito? Que cumpram as mitzvot? Mas se as cumprirem sem o coração, com falsas intenções, será é válido? Se sacrificam no templo e observam o ̌̌abat e as festividades, mas não se preocupam com os pobres, é válido?

$\mathrm{Na}$ visão dos profetas, a moralidade constitui o principal elemento da percepção que o homem tem de Deus: a essência da exigência que Deus faz ao homem não é apenas cultual, mas essencialmente moral.

Esse é o sentido da vida dos homens nessa terra de Deus.

Embora tenham formulado suas ideias para Israel e Judá, o insight dos profetas - ainda que utópico - exerceu e continua exercendo uma profunda influência no espírito humano.

O profeta Miquéias responde diretamente ao homem, e não mais à nação, formulando uma ideia inigualável no pensamento religioso da Antiguidade.

Ele te declarou, ó homem, o que é bom; (hig·gị̂ lo lok $\underline{k} \bar{a}$ 'ā senão que pratiques a justiça, e ames a benevolência,

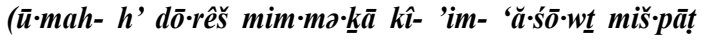

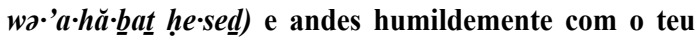

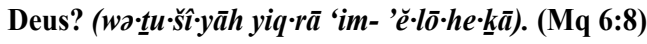

Deus espera que o homem - em cada pequena ação - seja justo, bondoso, e humilde; isto equivale a caminhar com Deus. 
Essa é uma poderosa doutrina moral, que ecoa no princípio formulado por Habacuc.

\section{$[\ldots]$ o justo vive por sua fé ('emunāa). (Hb 2:4)}

Em outras palavras, a fé na justiça de Deus é a base da existência. O homem não pode abandoná-la e simplesmente seguir vivendo.

Ao corrigir trabalhos de meus alunos, antes de lhes imputar uma nota, pergunto-me sempre: estou sendo justa? parece fácil, sim; mas, estou sendo bondosa? não exatamente... humilde?? hum... Pois é, não é nada simples seguir a fórmula de Miquéias.

Verificamos que a ideia de eleição incorre em grande responsabilidade, e não está em contradição com as atribulações e sofrimentos de Israel como nação, o que podemos compreender a partir das palavras do profeta Amós.

De todas as famílias da terra só a vós vos tenho conhecido; portanto eu vos punirei por todas as vossas

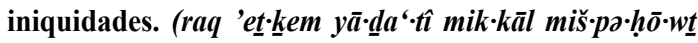

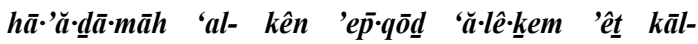

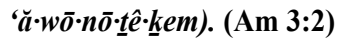

O verbo ladāat (conhecer), um dos mais expressivos e importantes no registro bíblico, denota uma relação de amor, fidelidade, penetração e compartilhamento da essência; um homem conhece sua mulher quando se amam física e emocionalmente e tornam-se uma só carne, remontando ao estágio primordial, anterior a sua diferenciação.

Essa relação de profunda interpenetração entre Deus e Israel imputa a Israel uma sentença: todas as suas transgressões serão punidas exemplarmente.

O sofrimento imposto a Israel, no entanto, não esgota seu significado na esfera da punição, mas alça voo como um caminho para a redenção, uma vez que representa a única possibilidade para a purificação salvadora.

O sofrimento, na teologia judaica, pertence ao plano divino da salvação.

As forças salvadoras da história não são poder e felicidades mundanas, mas 
o constante processo de purificação e aprimoramento por meio do sofrimento, da humildade, da prática dos princípios éticos.

Assim como o profeta Isaías, a exegese judaica vê no povo de Israel o servo sofredor de Deus. Na Bíblia hebraica, Deus ama sobretudo os sofredores. Eles abrirão o caminho para a salvação da humanidade.

Para o pensador Hermann Cohen (apud HOLZEY, 2000), na Alemanha do século XIX,

Deus ama em Israel nada mais do que a raça humana, porque Israel assume o jugo do sofrimento da redenção de toda a humanidade. Em seu sofrimento, Israel anseia pela era messiânica, quando "Deus será um e seu nome um para toda a raça humana" (Zc 14:9).

\section{Referências}

SOCIEDADE BÍBLICA DO BRASIL. Antigo Testamento Poliglota. Hebraico, grego, português, inglês. São Paulo: Vida Nova, 2003.

HOLZEY, Helmut. "Der systematische Ort der Religion der Vernunft im Gesamptwerk Hermann Cohens". In: HOLZEY, Helmut; MOTZKIN, Gabriel Gideon Hillel; WIEDEBACH, Hartwig (eds.). Religion der Vernunft aus den Quellen des Judentums: Tradition und Ursprungsdenken in Hermann Cohens Spätwerk. Hildesheim: Georg Olms, 2000. 